\title{
Isolasi Dan Karakterisasi Senyawa Steroid Dari Ekstrak Biji Mahoni (Swietenia mahagoni Jacq.)
}

\author{
Fadillah Maryam $^{1 *}$, Subehan ${ }^{2}$, Lilis Musthainah ${ }^{2}$ \\ ${ }^{1}$ Sekolah Tinggi Ilmu Farmasi Makassar \\ ${ }^{2}$ Universitas Hasanuddin, Makassar
}

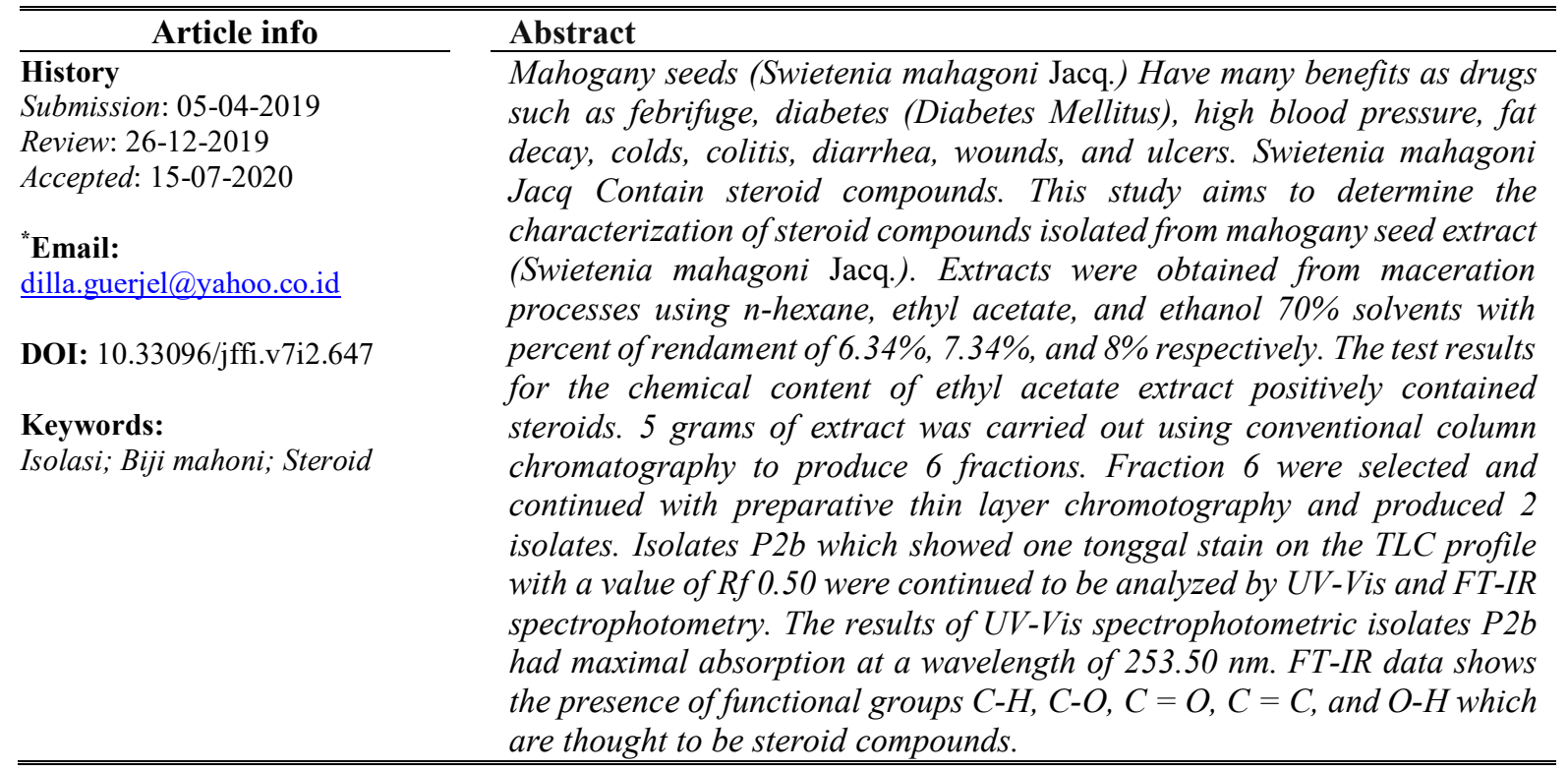

\section{Pendahuluan}

Indonesia kaya dengan aneka ragam flora dan fauna, keanekaragaman flora tersebut menjadikan negara kita sebagai salah satu negara di dunia yang ikut bangkit mengembangkan pengobatan herbal untuk penyembuhan berbagai penyakit dan kosmetika serta produk-produk suplemen untuk kesehatan. Data menyebutkan Sekitar 30.000 jenis flora yang ada di hutan tropika Indonesia, kurang lebih 9.600 spesies telah diketahui berkhasiat sebagai obat (Timumu, 2010).

Biji mahoni (Swietenia mahagoni Jacq.) memiliki banyak manfaat sebagai obat diantaranya sebagai obat penurun panas, obat kencing manis (Diabetes Mellitus), tekanan darah tinggi, peluruhan lemak, masuk angin, radang usus, diare, luka, dan bisul. Sebagian obat alamiah ini berasal dari alam atau tumbuh-tumbuhan, inilah taraf permulaan dari obat yang dikenal dengan obat tradisional (Dalimartha, 2006).

Secara empirik biji mahoni telah digunakan masyarakat dengan cara menumbuk biji mahoni sampai halus, ditambah dengan air hangat dan diminum secara langsung sehingga komponen biji mahoni bisa masuk kedalam tubuh. Namun jika tahan pahit, biji mahoni bisa dimakan mentahmentah (Hamzari, 2008). Penelitian terbaru menunjukkan bahwa biji mahoni memiliki banyak sekali aktivitas farmakologik seperti antibakteri, antimikroba, sitotoksik, antiulcer, antifungi, anti HIV, antiinflamasi, analgesik, antipiretik, hipoglikemik dan penghambatan aggregasi platelet (Bhurat et al, 2011).

Biji mahoni mempunyai kandungan kimia alkaloid, saponin, flavonoid, steroid, dan terpenoid. Penelitian sebelumnya yang telah dilakukan oleh (Mursiti, 2009) berhasil meneliti senyawa aktif flavonoid 7-hidroksi-2-(4-hidroksi-3-metoksifenil)-kroman-4-one dari biji mahoni ( $S$. mahagoni (L.) Jacq.) (Rasyad, 2012) telah berhasil mengisolasi ekstrak kasar triterpenoid sebanyak 21\% dari ekstrak etanol biji mahoni. (Mursiti, 2004) berhasil meneliti senyawa aktif alkaloid 3,6,7-trimetoksi-4-metil1,2,3,4-tetrahido-isoquinolin. (Anggrahini, 2010) berhasil mengisolasi senyawa aktif saponin 3-Otigloyl-6-0-asetilswietenolide sebanyak 14\% dari biji mahoni. (Aliyan, 2012) berhasil mengisolasi senyawa kimia aktif terpen dari fraksi aktif ekstrak biji mahoni.

Steroid berperan penting bagi tubuh dalam menjaga keseimbangan garam, mengendalikan metabolism dan meningkatkan fungsi organ seksual serta perbedaan fungsi biologis lainnya antara jenis kelamin. Steroid pada tumbuhan menunjukan efek menurunkan kolesterol dan antikarsinogenik (Nasruddin, 2017).

Melihat banyaknya penelitian tentang biji mahoni dan manfaatnya, maka perlu dilakukan 
penelitian tentang isolasi senyawa steroid dari biji mahoni (Swietenia mahagoni Jacq.). Hasil yang didapat akan dikarakterisasi menggunakan spektrofotometer UV-Vis dan FTIR.

\section{Metode Penelitian \\ II.1 Alat dan Bahan}

Alat yang digunakan pada penelitian ini adalah batang pengaduk, bejana maserasi, cawan porselin, corong, lampu UV 254 dan $366 \mathrm{~nm}$, hot plate, kertas saring, klem, kolom kromatografi, oven, penyemprot manual plat KLT, pipa kapiler, plat KLT preparatif silika gel $60 \mathrm{GF}_{254}$, seperangkat alat gelas, statif, sentrifus, spektrofotometer UV-Vis dan FTIR, tabung reaksi dan timbangan analitik, rotavapor.

Adapun bahan yang digunakan pada penelitian ini adalah biji mahoni (Swietenia mahagoni Jacq.), aquadest, etanol, etil asetat, nheksan, asam asetat anhidrat, asam sulfat p., kloroform, silika gel G-60(0,063-0,200).

\section{II.2 Pengambilan Sampel}

Sampel penelitian berupa biji mahoni diperoleh di Kabupaten Kolaka, Sulawesi Tenggara.

\section{II.3 Pengolahan Sampel}

Biji mahoni yang telah diperoleh dibersihkan terlebih dahulu (dipisahkan antara kulit dan bijinya). Sampel kemudian dirajang dan dikeringkan dengan cara diangin-anginkan kemudian dilakukan sortasi kering.

\section{II.4 Proses Ekstraksi}

Sampel diekstraksi menggunakan metode maserasi dengan cara dimasukkan sampel ke dalam bejana maserasi, ditambahkan pelarut n-Heksan selama 3 x 24 jam sambil sesekali diaduk. Setelah itu disaring hasil maserasi diambil ampas dan diulangi proses maserasi dengan cairan penyari yang baru sampai jernih. Diulangi proses menggunakan pelarut etil asetat dan etanol. Masing-masing ekstrak cair yang diperoleh diuapkan menggunakan rotavapor hingga diperoleh ekstrak kental.

\section{II.5 Identifikasi Fitokimia Steroid}

Sebanyak 0,5 g ekstrak kering dimasukkan ke dalam tabung reaksi, kemudian ditambahkan pereaksi Lieberman-Burchard (0,5 ml kloroform, ditambahkan $0,5 \mathrm{ml}$ asam asetat anhidrat dan $2 \mathrm{ml}$ asam sulfat P). Apabila terbentuk cincin merah kecoklatan atau ungu pada lapisan kedua sedangkan larutan pada bagian atas menjadi hijau atau ungu, hal ini menunjukkan bahwa ekstrak positif mengandung steroid (Depkes RI, 1987).

\section{II.6 Proses Pemisahan}

\section{Kromatografi Lapis Tipis}

Pemisahan dengan kromatografi lapis tipis dari ekstrak biji mahoni dilakukan untuk menentukan eluen yang digunakan untuk fraksinasi kromatografi kolom konvensional. Ditandai lempeng dengan batas atas dan batas bawah kemudian diaktifkan dalam oven pada suhu $115^{\circ} \mathrm{C}$ dalam waktu 15 menit. Kedalam vial dilarutkan masing-masing ekstrak kental etanol, etil asetat dan n-Heksan menggunakan pelarut awal dan selanjutnya ditotolkan pada lempeng yang telah diaktifkan. Selanjutkan dilakukan orientasi. Dimasukkan eluen ke dalam chamber, setelah itu dijenuhkan kemudian lempeng dielusi. Dilakukan pengamatan penampakan noda dengan menggunakan sinar UV $254 \mathrm{~nm}$ dan $366 \mathrm{~nm}$. Hasil elusi terbaik diperoleh eluen n-hexan : etil asetat (6:4) dipilih untuk proses fraksinasi selanjutnya.

\section{Fraksinasi dengan Kromatografi Kolom}

Ekstrak sebanyak 5 gram dilarutkan dengan $1 \mathrm{ml}$ n-Heksan, kemudian dimasukkan ke dalam kolom dibagian atas penjerap. Setelah itu dielusi dengan eluen campuran n-Heksan dan etil asetat dengan perbandingan (6:4) dalam $100 \mathrm{ml}$. Hasil yang keluar ditampung dalam vial masing-masing $10 \mathrm{ml}$ berupa fraksi. Fraksi tersebut kemudian digabungkan berdasarkan kesamaan profil KLT dan nilai Rf. Setelah itu fraksi-fraksi tersebut diuapkan kemudian ditimbang bobot fraksinya.

\section{Identifikasi Senyawa Steroid pada Fraksi}

Semua fraksi ditotolkan pada lempeng, dimasukkan dalam chamber yang telah dijenuhkan, kemudian dielusi menggunakan eluen. Keringkan dan dan disemprot menggunakan pereaksi penampak bercak Lieberman-Burchard (asam asetat anhidrat sebanyak $2 \mathrm{ml}, 2 \mathrm{ml}$ asam sulfat $\mathrm{P}$ dan 16 $\mathrm{ml}$ etanol p.a). Lempeng yang telah disemprot dipanaskan menggunakan hot plate.

\section{Isolasi dan Pemurnian}

Fraksi terpilih dari kromatografi kolom konvensional dilanjutkan pada Kromatografi Lapis Tipis Preparatif (KLTP). Ditotolkan fraksi pada plat silica gel $60 \mathrm{GF}_{254}$ kemudian dielusi menggunakan fase gerak eluen n-Heksan : etil asetat (6:4). Selanjutnya pita pada plat KLTP ditandai dan dikerok kemudian dilarutkan menggunakan pelarut etil asetat sebanyak $2 \mathrm{ml}$, kemudian disentrifus pada kecepatan $6 \quad(6.000 \quad \mathrm{rpm})$ selama 15 menit. Dipisahkan supernatan dan pelet. Ulangi proses sentrifus pada pelet seperti proses sebelumnya sebanyak 2 kali. Supernatan digabungkan, lalu diuapkan.

Uji kemurnian dilakukan dengan menggunakan KLT Dua Dimensi dan multi eluen nHeksan : etil asetat (6:4) dan kloroform : aseton (9:1). Jika isolat menunjukkan noda tunggal pada plat kromatografi maka isolat tersebut relatif murni secara KLT.

\section{Karakterisasi Isolat}

Karakterisasi isolat murni dilakukan dengan menggunakan alat spektrofotometer UV-Vis dan FTIR. 


\section{Hasil Dan Diskusi}

Dalam penelitian ini telah dilakukan isolasi dan karakterisasi senyawa steroid dari ekstrak biji mahoni (Swietenia mahagoni Jacq.) yang diperoleh dari Kabupaten Kolaka, Sulawesi Tenggara. Biji mahoni diekstraksi dengan metode maserasi bertingkat menggunakan 3 jenis pelarut berdasarkan tingkat kepolaran yang paling non polar hingga ke yang paling polar yaitu n-Heksan, etil asetat dan etanol.

Berdasarkan proses tersebut dihasilkan \% rendamen yang dapat dilihat pada Tabel 1 .

Tabel 1. Data rendamen hasil ekstraksi biji mahoni(Swietenia mahagoni Jacq.) dengan metode maserasi

\begin{tabular}{lccc}
\hline \multicolumn{1}{c}{ Sampel } & $\begin{array}{c}\text { Bobot } \\
\text { simplisia } \\
\text { (g) }\end{array}$ & $\begin{array}{c}\text { Bobot } \\
\text { ekstrak } \\
(\mathbf{g})\end{array}$ & $\begin{array}{c}\text { Rendemen } \\
\text { (\%) }\end{array}$ \\
\hline $\begin{array}{l}\text { Ekstrak n- } \\
\text { heksan }\end{array}$ & 150 & 9,513 & $6,34 \%$ \\
$\begin{array}{l}\text { Ekstrak etil } \\
\text { asetat }\end{array}$ & 150 & 11,024 & $7,34 \%$ \\
$\begin{array}{l}\text { Ekstrak } \\
\text { etanol 70\% }\end{array}$ & 150 & 12 & $8 \%$ \\
\hline
\end{tabular}

Ekstrak yang diperoleh selanjutnya dilakukan skrining fitokimia untuk mengetahui kandungan senyawa steroid dari ekstrak biji mahoni (Swetenia mahagoni Jacq.). Hasil dari skrining senyawa steroid dapat dilihat pada Gambar 1.

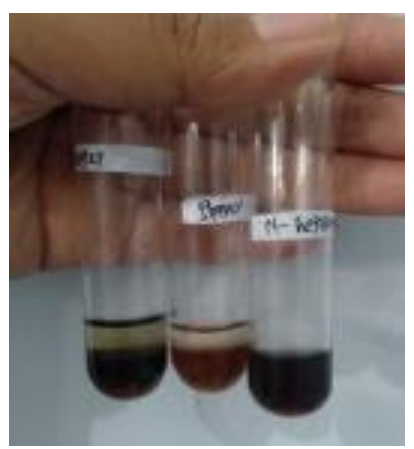

Gambar 1. Skrining fitokimia

Hasil identifikasi senyawa steroid beberapa ekstrak biji mahoni dapat dilihat pada Tabel 2.

Tabel 2. Identifikasi steroid ekstrak biji mahoni (Swietenia mahagoni Jacq.)

\begin{tabular}{|c|c|c|c|c|}
\hline Sampel & Hasil & Literatur & Pustaka & Ket. \\
\hline $\begin{array}{l}\text { Ekstrak n- } \\
\text { Heksan }\end{array}$ & $\begin{array}{l}\text { Batas kedua } r \text { larutan } \\
\text { terbentuk cincin merah } \\
\text { kecoklatan, larutan bagian } \\
\text { atas berwarna ungu dan } \\
\text { lapisan bawah berwarna } \\
\text { merah }\end{array}$ & $\begin{array}{l}\text { Terbentuk cincin merah } \\
\text { kecoklatan atau ungu } \\
\text { pada lapisan kedua, } \\
\text { sedangkan pada bagian } \\
\text { atas menjadi hijau. }\end{array}$ & $\begin{array}{c}\text { Depkes, RI } \\
\text { (1987) }\end{array}$ & $\begin{array}{c}+ \\
\text { Triterpenoi } \\
\mathrm{d}\end{array}$ \\
\hline $\begin{array}{l}\text { Ekstrak } \\
\text { Etil Asetat }\end{array}$ & $\begin{array}{l}\text { Terbentuk cincin coklat } \\
\text { kemerahan, lapisan bawah } \\
\text { ungu kemerahan dan lapisan } \\
\text { atas berwarna hijau }\end{array}$ & $\begin{array}{l}\text { Terbentuk cincin merah } \\
\text { kecoklatan atau ungu } \\
\text { pada lapisan kedua, } \\
\text { sedangkan pada bagian } \\
\text { atas menjadi hijau. }\end{array}$ & $\begin{array}{c}\text { Depkes, RI } \\
\text { (1987) }\end{array}$ & + Steroid \\
\hline $\begin{array}{l}\text { Ekstrak } \\
\text { Etanol } \\
70 \%\end{array}$ & $\begin{array}{l}\text { Terbentuk cincin } \\
\text { merah,lapisan atas bening } \\
\text { lapisan bawah merah bata }\end{array}$ & $\begin{array}{l}\text { Terbentuk cincin merah } \\
\text { kecoklatan atau ungu } \\
\text { pada lapisan kedua, } \\
\text { sedangkan pada bagian } \\
\text { atas menjadi hijau. }\end{array}$ & $\begin{array}{c}\text { Depkes, RI } \\
\text { (1987) }\end{array}$ & $\stackrel{+}{\text { Triterpenoi }}$ \\
\hline
\end{tabular}

Hasil identifikasi kandungan senyawa steroid berdasarkan uji skrining fitokimia pada beberapa ekstrak biji mahoni menunjukkan adanya senyawa steroid pada ekstrak etil asetat. Hal ini didukung oleh penelitian Meydia, dkk 2016 bahwa penggunaan pelarut etil asetat dalam ekstraksi senyawa steroid menghasilkan rendamen paling banyak dibanding pelarut $n$-heksan dan metanol dan dapat menarik senyawa steroid secara efektif.

Selanjutnya ekstrak biji mahoni sebanyak 5 gram dipisahkan dengan metode kromatografi kolom dengan fase diam silica gel G-60 dan fase gerak n-Heksan : etil asetat yang sebelumnya telah diuji kelarutannya, dilakukan secara kontinyu dari kepolaran yang rendah hingga kepolaran yang tinggi. Kromatografi kolom merupakan metode yang bagus untuk memisahkan komponen kimia yang jumlahnya sedikit dan hasilnya cepat diperoleh. Sebanyak 6 fraksi gabungan diperoleh dari 70 vial yang didasarkan atas profil nilai $\mathrm{Rf}$ dan pola pemisahan pada hasil kromatogram KLT. Hasil kromatografi kolom konvensional dapat dilihat pada Tabel 3. 
Tabel 3. Data hasil perhitungan Rf pada fraksi

\begin{tabular}{|c|c|c|c|}
\hline Fraksi & Berat (g) & UV $254 \mathrm{~nm}$ & UV $366 \mathrm{~nm}$ \\
\hline Fraksi 1 & 0,14 & $\mathrm{Rf}_{1}=0,83$ & $\mathrm{Rf}_{1}=0,83$ \\
\hline Fraksi 2 & 2,51 & $\mathrm{Rf}_{1}=0,76$ & $\begin{array}{l}\mathrm{Rf}_{1}=0,76 \\
\mathrm{Rf}_{2}=0,2\end{array}$ \\
\hline Fraksi 3 & 0,26 & - & $\mathrm{Rf}_{1}=0,18$ \\
\hline Fraksi 4 & 0,06 & - & - \\
\hline Fraksi 5 & 0,61 & $\mathrm{Rf}_{1}=0,67$ & $\mathrm{Rf}_{1}=0,67$ \\
\hline Fraksi 6 & 1,07 & $\begin{array}{l}\mathrm{Rf}_{1}=0,32 \\
\mathrm{Rf}_{2}=0,49 \\
\mathrm{Rf}_{3}=0,72\end{array}$ & $\begin{array}{l}\mathrm{Rf}_{1}=0,32 \\
\mathrm{Rf}_{2}=0,49 \\
\mathrm{Rf}_{3}=0,72\end{array}$ \\
\hline
\end{tabular}

Dari data hasil perhitungan Rf pada fraksi 1-6, fraksi 6 yang dilanjutkan pada tahap pemurnian karena memiliki pola pemisahan yang paling baik, dan nilai $\mathrm{Rf}$ yaitu 0,32 positif mengandung steroid setelah disemprot menggunakan pereaksi penampak bercak Lieberman-Burchard yang ditandai dengan muncul bercak noda berwarna hijau pada lempeng setelah penyemprotan.

Pemurnian pada teknik kromatografi lapis tipis preparatif dilakukan pada fraksi 6 menggunakan eluen n-Heksan : etil asetat (6:4). Hasil kromatografi lapis tipis preparatif, diperoleh 2 pita. Pita 1 dan 2 dikerok dan dilarutkan dengan etil asetat lalu dilakukan pemisahan isolat dari gel silika menggunakan teknik sentrifugasi. Isolat 1 dan 2 dilakukan pengujian dengan menggunakan pereaksi penampak bercak Lieberman-Burchard. Isolat pita 2 di KLTP kembali menggunakan eluen n-Heksan : etil asetat (6:4) diperoleh isolat pita $2 \mathrm{a}$ dan pita $2 \mathrm{~b}$, selanjutnya dilakukan pengujian menggunakan pereaksi penampak bercak Lieberman-Burchard. Dari hasil pengujian, isolat pita $2 \mathrm{~b}$ positif mengandung steroid yang ditandai dengan penampakan noda berwarna hijau pada plat KLT dengan nilai Rf 0,50 . Hal ini sejalan dengan penelitian yang dilakukan oleh Afriza, 2008 yang mengisolasi senyawa triterpenoida/steroid dari ekstrak n-Heksana daun tumbuhan ruku-ruku (Ocimum sanctum 1.) dengan nilai Rf 0,50.

Isolat yang diperoleh kemudian dilanjutkan uji kemurnian dengan metode kromatografi lapis tipis dua dimensi dan multi-eluen yaitu n-Heksan : etil asetat (6:4), kloroform : aseton (9:1). Hasil elusi multi eluen ini dapat dilihat pada Gambar 2 tetap menunjukkan adanya noda tunggal. Berdasarkan hal tersebut, diduga isolat yang diperoleh telah murni. Isolat pita $2 \mathrm{~b}$ yang diperoleh selanjutnya dianalisis menggunakan instrumen UV-Vis dan IR.
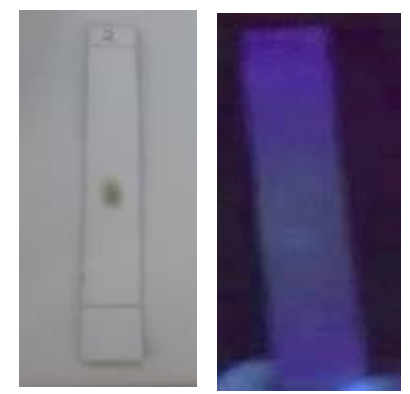

Gambar 2. Penyemprotan pereaksi

Dari hasil spektrum UV-Vis diperoleh panjang gelombang maksimum pada $253,50 \mathrm{~nm}$. Transisi pada panjang gelombang senyawa isolat menunjukkan pergeseran batokromik yang disebabkan oleh perubahan pelarut atau adanya suatu ausokrom (Sudjadi, 1983 dan Mulja, 1995). Hal ini sejalan dengan penelitian uswatun hasanah 2017 yang mengisolasi senyawa steroid dari teripang batu dengan hasil spektrum UV-Vis diperoleh panjang gelombang maksimum $252 \mathrm{~nm}$.

Tabel 4. Hasil Pembacaan Spektrum IR

\begin{tabular}{|c|c|c|c|c|c|}
\hline \multirow[b]{2}{*}{ No. } & \multirow{2}{*}{$\begin{array}{c}\text { Bilangan } \\
\text { Gelombang } \\
\text { Isolat }\left(\mathrm{cm}^{-1}\right)\end{array}$} & \multicolumn{3}{|c|}{ Daerah Frekuensi $\left(\mathrm{cm}^{-1}\right)$} & \multirow{2}{*}{$\begin{array}{c}\text { Prediksi Gugus } \\
\text { Fungsi }\end{array}$} \\
\hline & & $\begin{array}{c}\text { Pustaka } \\
\text { Silverstein }\end{array}$ & $\begin{array}{l}\text { Pustaka } \\
\text { Harmita }\end{array}$ & $\begin{array}{c}\text { Pustaka } \\
\text { Fessenden }\end{array}$ & \\
\hline 1. & 742,59 & $675-870$ & $1000-650$ & - & $\begin{array}{c}\text { C-H } \\
\text { (Alkena) }\end{array}$ \\
\hline 2. & 1124,50 & $1300-1080$ & $1300-1000$ & - & $\begin{array}{c}\mathrm{C}-\mathrm{O} \\
\text { (Ester) }\end{array}$ \\
\hline 3. & 1273,02 & $1300-1080$ & $1300-1000$ & - & $\begin{array}{c}\mathrm{C}-\mathrm{O} \\
\text { (Ester) }\end{array}$ \\
\hline 4. & 1462,04 & - & - & $1450-1600$ & $\begin{array}{c}\mathrm{C}=\mathrm{C} \\
\text { (Alkena) }\end{array}$ \\
\hline 5. & 1539,20 & $1600-1500$ & - & - & $\mathrm{C}=\mathrm{C}$ \\
\hline
\end{tabular}




\begin{tabular}{cccccc}
\hline 6. & 1730,15 & $1760-1690$ & $1730-1750$ & - & $\begin{array}{c}\text { (Aromatik) } \\
\mathrm{C}=\mathrm{O} \\
\text { (Ester) } \\
\text { 7. }\end{array}$ \\
2924,09 & $2960-2850$ & $3000-3200$ & - & $\begin{array}{c}\text { C-H } \\
\text { (Alkana) } \\
\text { O-H } \\
\text { (Bebas) }\end{array}$ \\
\hline
\end{tabular}

Data pembacaan hasil spektrofotometri infra merah (IR) pada Tabel 4 menunjukkan adanya serapan dengan intensitas kuat pada frekuensi 742,59 dan $2924,09 \mathrm{~cm}^{-1}$ mengindikasikan adanya gugus $\mathrm{C}-\mathrm{H}$. Kemudian adanya serapan dengan intensitas kuat pada frekuensi $1124,50 \mathrm{~cm}^{-1}$ dan $1273,02 \mathrm{~cm}^{-1}$ mengindikasikan adanya gugus $\mathrm{C}-\mathrm{O}$. Terdapat intensitas sedang-lemah pada frekuensi $1462,04 \mathrm{~cm}^{-1}$ dan $1539,20 \mathrm{~cm}^{-1}$ menunjukkan adanya ikatan $\mathrm{C}=\mathrm{C}$. Terdapat intensitas sedang pada panjang gelombang 3448,72 yang mengindikasikan adanya gugus $\mathrm{O}-\mathrm{H}$ bebas (Harmita, 2014 dan Silverstein, 2005).
Dari hasil analisis data spektrofotometri Infra Red (IR) yang dapat dilihat pada Gambar 3, diduga isolat pita $2 \mathrm{~b}$ menunjukkan bahwa isolat merupakan senyawa siklik (golongan steroid). Vibrasi regang O-H pada bilangan $3448,72 \mathrm{~cm}^{-1}$ dan regang $\mathrm{C}-\mathrm{O}$ pada bilangan gelombang $1124,50 \mathrm{~cm}^{-1}$ dan $1273,02 \mathrm{~cm}^{-1}$ juga mendukung bahwa isolat merupakan senyawa steroid karena memiliki gugus hidroksil dan didukung oleh data spektrofotometri UV-Vis dengan absorbansi maksimum pada panjang gelombang 253,50 $\mathrm{nm}$ yang diduga menunjukkan adanya steroid.

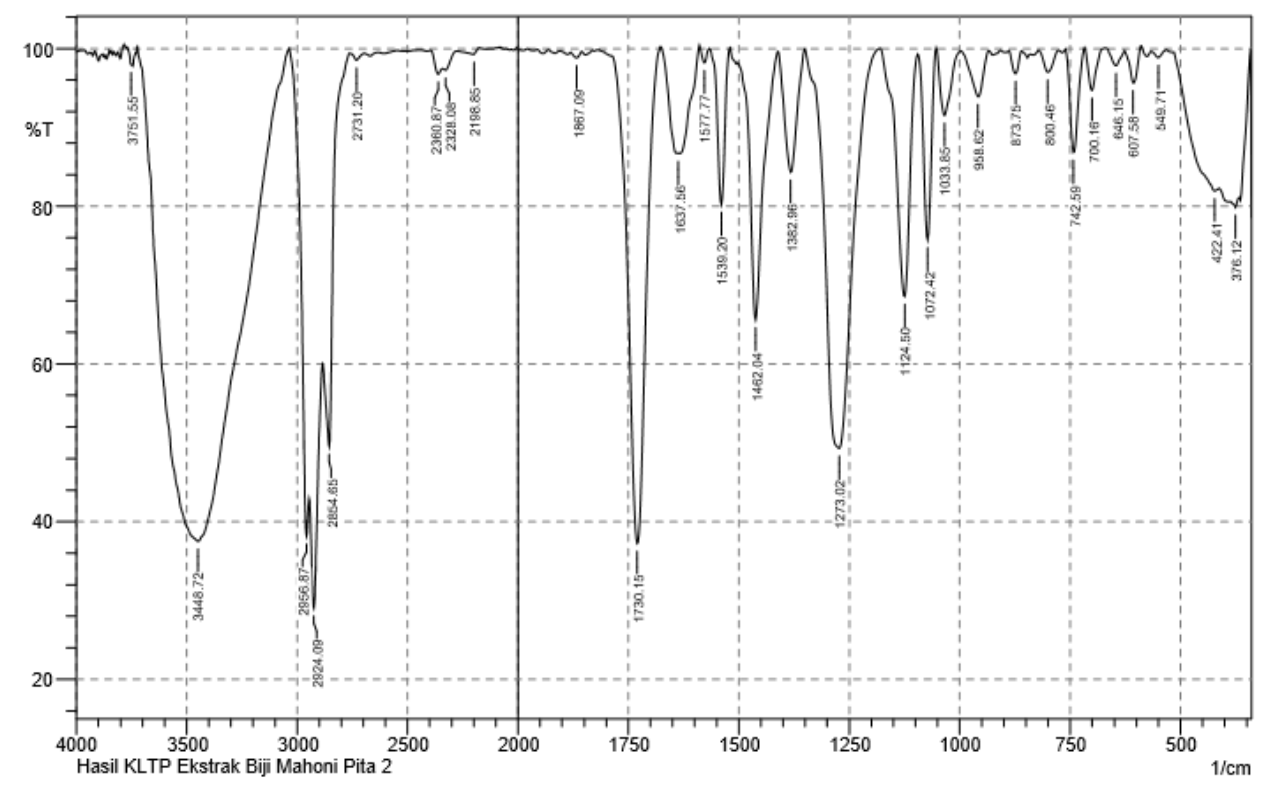

Gambar 3. Analisis Spektrofotometri FTIR

\section{Kesimpulan}

Berdasarkan hasil penelitian isolasi dan karakterisasi senyawa steroid ekstrak etil asetat biji mahoni, isolat $\mathrm{P} 2 \mathrm{~b}$ yang diperoleh diduga merupakan senyawa steroid yang didukung oleh uji golongan senyawa pada ekstrak yang menunjukkan hasil positif mengandung steroid, dan hasil identifikasi isolat menggunakan pereaksi spesifik positif mengandung steroid serta didukung oleh data spektrofotometri UV-Vis yang mempunyai absorbansi maksimal pada panjang gelombang 253,50 $\mathrm{nm}$ dan data spektrofotometri FT-IR yang menunjukkan gugus fungsi $\mathrm{C}-\mathrm{H}, \mathrm{C}-\mathrm{O}, \mathrm{C}=\mathrm{C}, \mathrm{C}=\mathrm{O}$ dan $\mathrm{O}-\mathrm{H}$.

\section{Daftar Pustaka}

Aliyan, H. 2012. Uji penghambatan aktivitas alfaglukosidase dan identifikasi golongan senyawa kimia dari fraksi aktif ekstrak biji mahoni. UI: Jakarta

Anggrahini, D. 2010. Isolasi dan identifikasi senyawa saponin dari biji mahoni (swietenia macrophylla, king). FMIPA UNNES: Semarang

Dalimartha, S. 2006. Biji Mahoni (Swietenia mahagoni Jacq) Atlas Tumbuhan Obat Indonesia. Vol 2, 131-134. Trubus Agriwidya: Jakarta 
Dalimartha, S. 2009. Ramuan tradisional untuk pengobatan diabetes mellitus cetakan 6.

Hamzari. 2008. Identifikasi Tanaman Obat-Obatan Yang Dimanfaatkan Oleh Masyarakat Sekitar Hutan Tabo-Tabo. Jurnal Hutan dan masyarakat: Tadulako

Harmita. 2014. Analisis Fisikokimia, Departemen FMIPA UI: Depok.

Harianja, A. 2008. Tumbuhan Obat dan Khasiatnya, Cetakan Kelima

Meydia, Suwandi, R. dan Suptijah, P.2016. Isolasi Senyawa Steroid dari Teripang Gama dengan Berbagai Jenis Pelarut.

Mursiti, S. 2004. Identifikasi senyawa alkaloid dalam biji mahoni bebas minyak (swietenia macrophylla, king) dan efek biji mahoni terhadap penurunan kadar glukosa darah tikus putih (Rattus novergicus). UGM: Yogyakarta

Mursiti, S. 2009. Isolasi, karakterisasi, dan uji aktivitas hipoglikemik senyawa dalam biji mahoni bebas minyak dan minyak biji mahoni (Swietenia Macrophylla King)

Nasruddin, Wahyono, Mustofa, Ratna Asmah. 2017. Isolasi Senyawa Steroid dari Kulit Senggugu (Clerodendrum serratum L.Moon). Universitas Gadjah Mada: Yogyakarta

Silverstein, R.M., Webster, F.X. dan and Kiemle, D.J., 2005. Spectrometric Identification of Organic Compounds 7th edition, John Willey \& Sons. New York.

Sudjadi, M.S., 1983. Penetuan Struktur Senyawa Organik, Bandung, Ghali : Indonesia. 